\title{
Nuclear Expression Loss of SSBP2 Is Associated with Poor Prognostic Factors in Colorectal Adenocarcinoma
}

\author{
Yumin Chung ${ }^{1} \oplus$, Hyunsung Kim ${ }^{2} \oplus$, Seongsik Bang ${ }^{2}$, Kiseok Jang ${ }^{2}$, Seung Sam Paik ${ }^{2, *}$ \\ and Su-Jin Shin $3, * \mathbb{D}$ \\ 1 Department of Pathology, Kangbuk Samsung Hospital, Sungkyunkwan University College of Medicine, \\ Seoul 03181, Korea; umin0501@naver.com \\ 2 Department of Pathology, Hanyang University College of Medicine, Seoul 04763, Korea; \\ hhnt5841@gmail.com (H.K.); grypony@naver.com (S.B.); medartisan@hanyang.ac.kr (K.J.) \\ 3 Department of Pathology, Gangnam Severance Hospital, Yonsei University College of Medicine, \\ Seoul 06273, Korea \\ * Correspondence: sspaik@hanyang.ac.kr (S.S.P.); nanmabup@gmail.com (S.-J.S.); \\ Tel.: +82-2-2019-3540 (S.-J.S.); Fax: +82-2-3463-2103 (S.-J.S.)
}

Received: 12 November 2020; Accepted: 15 December 2020; Published: 16 December 2020

\begin{abstract}
Single-stranded DNA binding protein 2 (SSBP2) is involved in DNA damage response and may induce growth arrest in cancer cells, having a potent tumor suppressor role. SSBP2 is ubiquitously expressed and the loss of its expression has been reported in various tumor types. However, the correlation between SSBP2 expression and colorectal cancer (CRC) prognosis remains unclear. SSBP2 nuclear expression was evaluated immunohistochemically in 48 normal colonic mucosae, 47 adenomas, 391 primary adenocarcinomas, and 131 metastatic carcinoma tissue samples. The clinicopathological factors, overall survival (OS), and recurrence-free survival were evaluated, and associations with the clinicopathological parameters were analyzed in 391 colorectal adenocarcinoma patients. A diffuse nuclear SSBP2 expression was detected in all normal colonic mucosa and adenoma samples. SSBP2 expression loss was observed in $131(34.3 \%)$ primary adenocarcinoma and $100(76.3 \%)$ metastatic carcinoma samples. SSBP2 expression was significantly associated with poor prognostic factors, such as vascular invasion $(p=0.005)$, high $\mathrm{pT}$ category $(p=0.045)$, and shorter OS ( $p=0.038)$, using univariate survival analysis. Nuclear SSBP2 expression loss was significantly observed in colorectal carcinoma and metastatic carcinoma tissues, being associated with poor prognostic factors. SSBP2 acts as a tumor suppressor and may be used as a CRC prognostic biomarker.
\end{abstract}

Keywords: SSBP2; colon cancer; immunohistochemistry; prognosis

\section{Introduction}

Colorectal cancer (CRC) is a leading cause of cancer-related morbidity and mortality worldwide, accounting for approximately about 700,000 deaths per year. Based on the GLOBOCAN series of the International Agency for Research on Cancer (IARC), CRC is the third most common cancer $(10 \%$ of the total number) in men and the second most common ( $9.2 \%$ of the total number) in women [1].

$\mathrm{CRC}$ is a heterogeneous disease that exhibits variable underlying molecular changes, with genetic instability. Two major mechanisms of genetic instability include chromosomal instability (CIN, the most common type) and microsatellite instability (MSI) [2]. CIN includes changes in the chromosome number and structure, such as deletions, gains, translocations, and other chromosomal rearrangements [3]. MSI occurs due to a defective DNA mismatch repair. For example, Lynch syndrome or hereditary nonpolyposis colorectal cancer syndrome is caused by inherited mutations in one of the mismatch 
repair (MMR) genes (predominantly MLH1 and MSH2) [4]. Markowits et al. described the three most important molecular pathways for CRC development [5]. The first pathway involves genomic instability due to CIN, MSI, and aberrant DNA methylation. The second pathway involves mutational inactivation of tumor-suppressor genes, such as $A P C, T P 53$, and TGF- $\beta$. The third pathway involves the activation of oncogenes, such as RAS, BRAF, and phosphatidylinositol 3-kinase. Recently, promoter methylation has been studied in several human malignancies. Methylation leads to transcriptional silencing and plays a crucial role in the loss of expression of tumor suppressor or DNA repair genes [6,7]. Somatic mutations of the adenomatous polyposis coli (APC) tumor suppressor gene are common in sporadic CRC [8]. However, in up to $20 \%$ of CRC tumors, APC mutation is not present and gene inactivation via transcriptional silencing due to promoter hypermethylation led to the loss of $A P C$ function. Esteller et al. found that the APC promoter is hypermethylated in $18 \%$ of primary sporadic CRCs, and that methylation affected wild-type APC in $95 \%$ of cases [9].

Currently used tests in clinics related to prognosis and treatment in CRCs include MSI testing, mutations in $R A S$, and EGFR immunohistochemical test for anti-EGFR therapy. For example, MMR deficiency can be determined by performing immunohistochemical staining for the four major proteins MLH1, MSH2, MSH6, and PMS2 that make up the MMR system. In general, deficient mismatch repair (dMMR) is defined as when the nuclear expression of one or more MMR proteins (MLH1, PMS2, MSH2, or MSH6) is lost [10]. Approximately $20 \%$ of stage II and stage III CRCs exhibit a dMMR/MSI phenotype and are associated with a better prognosis than pMMR (proficient mismatch repair)/MSS (microsatellite stable) tumors [11]. Several studies have provided evidence that patients with dMMR tumors do not benefit from adjuvant chemotherapy [12-14]. Therefore, the MMR protein test plays an important role in decision making for treatment regimen.

Many studies have been conducted to find biomarkers related to the prognosis of CRCs. A recently published review article identified biomarkers associated with treatment response (PTEN, AREG, EREG, PI3K), metastasis and progression risk (ALDH1, BRAF V600E, CDX2, leptin, c-MET), and survival rate (ARID3A, FOXP3, HIF-1 $\alpha$, Ran) [15]. Although many biomarkers have been studied, most of them, except for RAS mutations and MSI status, are currently not clinically useful. Therefore, further research for the new clinically useful biomarker is needed.

The human single stranded DNA binding protein 2 (SSBP2) gene was first identified in primary leukemic blasts and was found to be translocated and deleted in myelodysplasia and acute myelogenous leukemia (AML). SSBP2 expression has been detected in hematopoietic and non-hematopoietic tissues [16,17]. The loss of SSBP2 expression is associated with various types of malignancies, such as esophageal squamous cell carcinoma, prostate cancer, gallbladder cancer, and acute myeloid leukemia [18-21]. SSBP2 was shown to play a tumor-suppressive role in esophageal squamous cell carcinoma via inhibition of the Wnt signaling pathway [18]. In addition, Maldonado et al. found that a decreased SSBP2 expression was associated with an increased risk of recurrence in late stage prostate cancer [22]. Liang et al. described that the candidate myeloid leukemia suppressor gene encoding sequence-SSBP2 from chromosome 5q13.3 was frequently deleted in AML. They identified the frequent loss of SSBP2 protein expression in human AML cell lines using highly specific antibodies. Surprisingly, the inducible expression of SSBP2 was accompanied by a downregulation of C-MYC expression. In addition, they briefly mentioned the possibility that SSBPs may directly repress C-MYC expression in CRC [13]. However, He et al. analyzed the association between C-MYC and CRC prognosis in a meta-analysis. They concluded that C-MYC was not associated with CRC prognosis [23]. Meanwhile, several studies on promoter methylation of SSBP2 in tumors have shown that SSBP2 is one of the genes that are downregulated by methylation $[18,20,21,24,25]$.

The relationship between SSBP2 and CRC has been reported in a few studies. First, Andersen et al. described that SSBP2, a transcription factor upregulated by Wnt inactivation, was downregulated in CRC by performing quantitative real-time RT-PCR (qRT-PCR). However, validation using immunohistochemistry was not performed [26]. Second, Shannon et al. found that SSBP2 may be a potential biomarker, identifying it and optimizing it for immunohistochemistry (IHC) in CRC with peritoneal metastasis. Validation was 
performed on patients with colorectal peritoneal metastasis (CPM) that underwent CRS (cytoreductive surgery)-HIPEC (hyperthermic intraperitoneal chemotherapy) $(n=62)$, using IHC. They described that patients exhibiting a lower expression of SSBP2 potentially had a poorer overall survival (OS) and a shorter disease-free survival (DFS), compared to those with a higher expression, although they were not statistically significant [27]. Third, Perilli et al. found that an increased level of miR-182-5p (miR-182), one of the most upregulated oncogenic microRNAs (miRNAs) in CRC, was associated with a significant decrease in SSBP2 mRNA levels in the tumor tissues, compared to matched normal mucosa [28].

In this study, we examined the expression of SSBP2, its prognostic significance, and its association with the clinicopathological features in CRC patients.

\section{Materials and Methods}

\subsection{Patients}

We retrospectively collected data from patients with colorectal adenocarcinoma who underwent curative surgery at the Hanyang University Hospital, Seoul, between January 2005 and December 2010. A total of 391 patients were included after excluding patients who received neoadjuvant chemotherapy and/or radiation therapy, the ones who died within 30 days of surgery, or had insufficient tissue material for analysis. Primary colorectal adenocarcinoma tissues $(n=391)$, matched normal colonic mucosa tissues ( $n=48$; randomly selected from 391 cases), and matched metastatic carcinoma tissues ( $n=131 ; 92$ lymph node metastasis and 39 distant organ metastasis) were obtained from the colorectal adenocarcinoma patients. In addition, 40 patients diagnosed with adenoma with low-grade dysplasia who underwent biopsy or polypectomy at the Hanyang University Hospital, Seoul, between January 2013 and December 2014, were randomly selected. Four patients diagnosed with adenoma exhibited multiple adenomatous polyps, and 47 adenoma tissue samples were obtained from them.

A total of 617 formalin-fixed, paraffin-embedded tissue samples were collected and 2.0-mm-core tissue microarray (TMA) blocks were constructed with one representative core for each case. The percentage of tumors in each cancer tissue core was greater than $70 \%$. Clinical data, including age, sex, tumor location, tumor size, histologic grade, lymphovascular invasion, perineural invasion, tumor deposit, tumor budding, and TNM (tumor $(\mathrm{T})$, nodes $(\mathrm{N})$, and metastases $(\mathrm{M})$ ) staging were obtained from the medical records. Staging was determined according to the American Joint Committee on Cancer (8th edition) [29]. This study was approved by the Hanyang University Hospital (No. 2016-12-030-001), and the requirement for informed consent was waived.

\subsection{Immunohistochemical Stainings and Interpretation}

SSBP2 expression was evaluated using immunohistochemical staining of $4-\mu \mathrm{m}$-thick sections from TMA blocks. Rabbit monoclonal anti-SSBP2 antibody (1:100, ab177944, Abcam, Cambridge, UK) was used. The sections were first deparaffinized in xylene and then rehydrated through a graded ethanol series. For antigen retrieval, we heated the samples to $100{ }^{\circ} \mathrm{C}$ for $30 \mathrm{~min}$ in sodium citrate buffer ( $\mathrm{pH}$ 6.0). Endogenous peroxidase activity was blocked using a peroxidase blocking solution (S2023, DakoCytomation, Carpinteria, CA, USA). TMA slides were incubated with primary antibodies at $4{ }^{\circ} \mathrm{C}$ overnight and then incubated with the labeled polymer (DAKO REAL EnVision/HRP, K5007, DakoCytomation, Glostrup, Denmark) for $30 \mathrm{~min}$ at room temperature. Then, 3,3-diaminobenzidine was used as a chromogen for visualization, and Mayer's hematoxylin counterstain was applied.

The expression of SSBP2 was evaluated according to the extent of tumor cell nuclear staining, using a light microscope, by two pathologists (YM and SS) who were blinded to the clinical data. The patients were subsequently subdivided into negative (proportion of positive tumor cells $\leq 10 \%$ of the total tumor cells) and positive (proportion of positive tumor cells $>10 \%$ of the total tumor cells) subgroups (Figure 1). The evaluation of tumor positivity for a given marker is frequently performed using predetermined standard cutoffs, such as 10\% [30-35]. The adoption of a categorical scoring system for interpretation simplifies the division of positive and negative groups by pathologists and is 
further supported by practical observer reproducibility. However, it is assumed that no additional relevant data from the detailed analysis of protein expression of $10-100 \%$ will be provided in the production of the results.

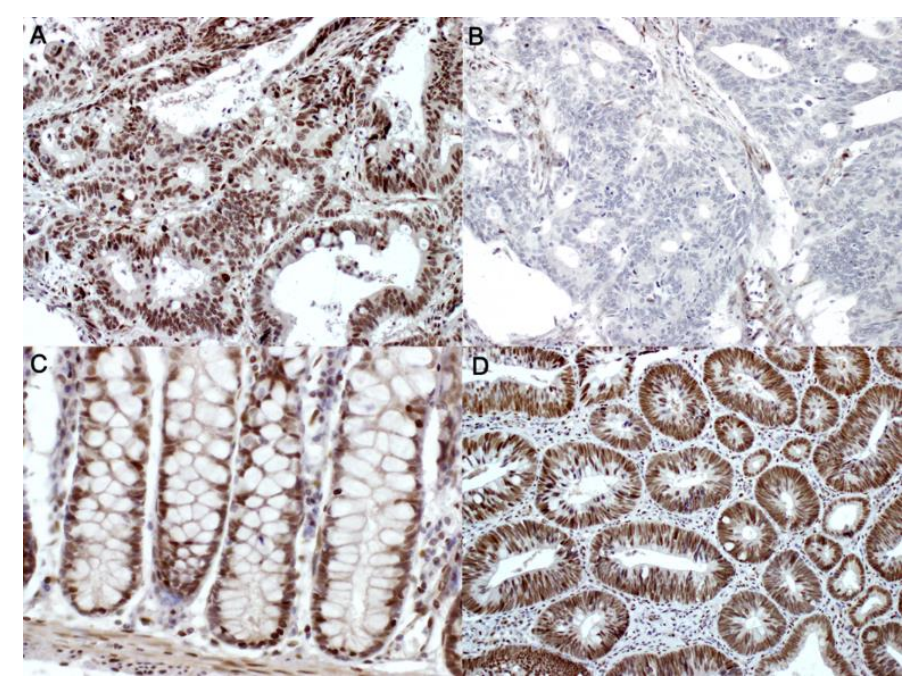

Figure 1. Immunohistochemical staining of single-stranded DNA-binding protein 2 (SSBP2). Representative figures of SSBP2-positive $(\mathbf{A}, \times 200)$ and SSBP2-negative $(\mathbf{B}, \times 200)$ colorectal adenocarcinoma, SSBP2-positive normal colonic tissues $(\mathbf{C}, \times 200)$, and SSBP2-positive tubular adenoma $(\mathrm{D}, \times 200)$.

\subsection{Statistical Analyses}

Pearson's chi-square test or Fisher's exact test were used to evaluate any potential association between SSBP2 expression and the clinicopathological parameters, including age, sex, tumor location, tumor size, histologic grade, lymphatic invasion, vascular invasion, perineural invasion, tumor deposit, tumor budding, and AJCC (American Joint Committee on Cancer) staging. The differences in SSBP2 expression between groups were compared using the Mann-Whitney U test and Wilcoxon signed-rank test. The overall survival (OS) was defined as the duration between the date of curative resection and the date of death or the last follow-up. Recurrence-free survival (RFS) was defined as the duration between curative resection and the date of the first recurrence. Kaplan-Meier survival curves, the log-rank test, and the Cox proportional hazard regression model were used for survival analysis. Two-sided $p$-values $<0.05$ were considered statistically significant. All statistical analyses were performed using SPSS version 24.0 (SPSS Inc., Chicago, IL, USA).

\section{Results}

\subsection{Patient Characteristics and SSBP2 Expression}

The median age of patients with colorectal adenocarcinoma and adenoma was 64 years (range, 27-89 years) and 60 years (range, 30-82 years), respectively, and the male-to-female ratios were 1.56:1 and 1:1, respectively. The median follow-up period for the patients in this study was 108 months (range, 1-166 months). Among the 391 colorectal adenocarcinoma patients, 25 (6.4\%) patients exhibited metastatic disease at the time of initial diagnosis, $81(20.7 \%)$ patients had recurrence at the time of analysis, and 154 (39.4\%) patients had died at the time of analysis.

Overall, a loss of nuclear SSBP2 expression was observed in 134 (34.3\%) primary colorectal adenocarcinoma and $100(76.3 \%)$ metastatic carcinoma tissues, while all normal colonic mucosa and adenoma tissues showed a positive SSBP2 expression. The mean values (\%) of SSBP2 expression were 99.17, 94.47, 25.38, and 9.92, respectively. SSBP2 expression was significantly decreased in primary adenocarcinoma and metastatic carcinoma tissues (all, $p<0.001$; Table 1, Figure 2A). There was 
no significant difference between the lymph node metastasis and distant organ metastasis groups ( $p=0.389$; Figure 2B). Among the 39 distant organ metastasis cases, 30 affected the liver, six affected the lungs, and three affected the ovaries; SSBP2 expression was significantly lower in the liver than in other organs (mean value $=7.3 \%$ vs. $32.2 \%, p=0.011$ ). A paired-samples Wilcoxon signed-rank test was conducted to compare SSBP2 expression in distant organ metastatic tissues and matched primary CRC tissues. There was a significant difference in the expression proportion (mean value $=32.7 \%$ vs. $16.8 \%, p=0.008)$.

Table 1. Expression pattern of SSBP2 in normal colonic mucosa, adenoma, primary adenocarcinoma, and metastatic adenocarcinoma.

\begin{tabular}{ccccc}
\hline $\begin{array}{c}\text { SSBP2 Nuclear } \\
\text { Expression }\end{array}$ & $\begin{array}{c}\text { Normal Mucosa } \\
(\boldsymbol{n}=\mathbf{4 8})\end{array}$ & $\begin{array}{c}\text { Adenoma } \\
(\boldsymbol{n}=\mathbf{4 7})\end{array}$ & $\begin{array}{c}\text { Primary Adenocarcinoma } \\
(\boldsymbol{n}=391)\end{array}$ & $\begin{array}{c}\text { Metastatic Carcinoma } \\
(\boldsymbol{n}=\mathbf{1 3 1})\end{array}$ \\
\hline $\begin{array}{c}\text { Positive } \\
\text { Negative }\end{array}$ & $\begin{array}{c}\boldsymbol{p} \text {-Value } \\
(100.0 \%)\end{array}$ & $\begin{array}{c}47(100.0 \%) \\
0(0.0 \%)\end{array}$ & $\begin{array}{c}257(65.7 \%) \\
134(34.3 \%)\end{array}$ & $\begin{array}{c}31(23.7 \%) \\
100(76.3 \%)\end{array}$ \\
\hline $\begin{array}{c}\text { Positive cell proportion, } \% \\
\text { (Mean } \pm \text { SD) }\end{array}$ & $99.17 \pm 5.77$ & $94.47 \pm 7.96$ & $25.38 \pm 20.80$ & $9.92 \pm 18.46$ \\
\hline a & & & $<0.001 \mathrm{~b}$ \\
\hline
\end{tabular}

${ }^{\text {a }}$ Two-sided Pearson's chi-square test; ${ }^{b}$ Mann-Whitney U test. Abbreviations: SD, standard deviation.
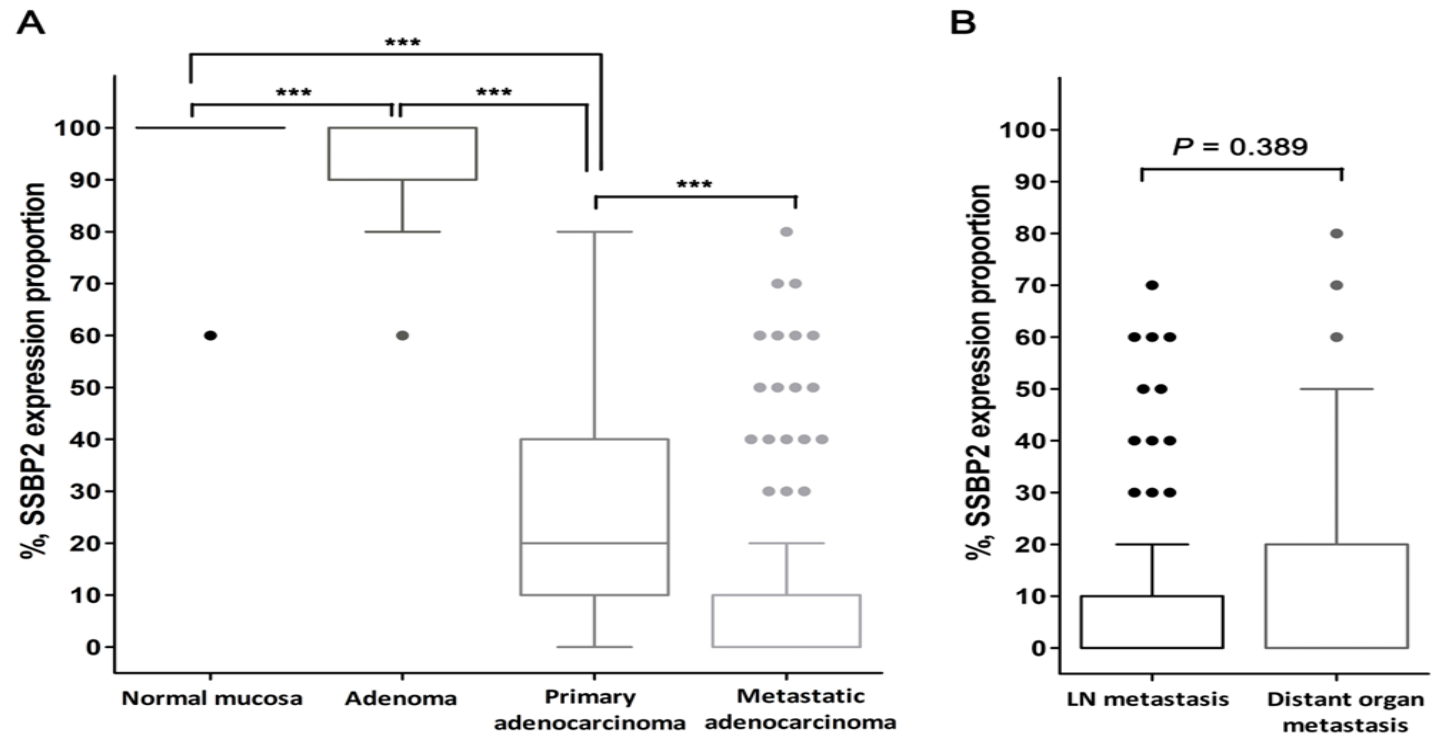

Figure 2. Box and whisker plots of SSBP2 expression proportion. (A) SSBP2 expression was significantly decreased with cancer progression $\left.{ }^{* * *} p<0.001\right)$. (B) There was no significant difference between the lymph node metastasis and distant organ metastasis groups. (Horizontal line in the middle of each box, median; boxes, 25 percentile 75 percentile; whiskers, $1.5 \times$ interquartile range from each boundary of the boxes; circles, outlier values with corresponding case number; $p$-value using Mann-Whitney U test, two-tailed.)

\subsection{Correlation between SSBP2 Expression and Clinicopathological Features}

To assess the correlation between SSBP2 expression and the clinicopathological parameters, SSBP2 expression was evaluated in 391 primary colorectal adenocarcinomas. The loss of SSBP2 expression was more frequently observed in tumors with vascular invasion $(p=0.005)$ and a high pT category $(p=0.045)$. There was no significant correlation between SSBP2 expression and other clinicopathological parameters (Table 2). 
Table 2. SSBP2 expression and clinicopathological parameters in colorectal adenocarcinoma patients $(n=391)$.

\begin{tabular}{|c|c|c|c|}
\hline Parameters & $\begin{array}{l}\text { SSBP2-Negative } \\
\quad(n=134)\end{array}$ & $\begin{array}{l}\text { SSBP2-Positive } \\
\quad(n=257)\end{array}$ & $p$-Value \\
\hline Age & & & 0.507 \\
\hline$<65$ years & $72(35.8 \%)$ & $129(64.2 \%)$ & \\
\hline$\geq 65$ years & $62(32.6 \%)$ & $128(67.4 \%)$ & \\
\hline Sex & & & 0.924 \\
\hline Male & $82(34.5 \%)$ & $156(65.5 \%)$ & \\
\hline Female & $52(34.0 \%)$ & $101(66.0 \%)$ & \\
\hline Tumor location & & & 0.062 \\
\hline Right side & $19(24.1 \%)$ & $60(75.9 \%)$ & \\
\hline Transverse and Left side & $13(30.2 \%)$ & $30(69.8 \%)$ & \\
\hline Rectosigmoid & $102(37.9 \%)$ & $167(62.1 \%)$ & \\
\hline Histologic grade & & & 0.061 \\
\hline G1 (well differentiated) & $7(24.1 \%)$ & $22(75.9 \%)$ & \\
\hline G2 (moderately differentiated) & $55(30.1 \%)$ & $128(69.9 \%)$ & \\
\hline G3 (poorly differentiated) & $72(40.2 \%)$ & $107(59.8 \%)$ & \\
\hline Lymphatic invasion & & & 0.116 \\
\hline Absent & $54(30.2 \%)$ & $125(69.8 \%)$ & \\
\hline Present & $80(37.7 \%)$ & $132(62.3 \%)$ & \\
\hline Vascular invasion & & & 0.005 \\
\hline Absent & $98(31.0 \%)$ & $218(69.0 \%)$ & \\
\hline Present & $36(48.0 \%)$ & $39(52.0 \%)$ & \\
\hline Perineural invasion & & & 0.123 \\
\hline Absent & $62(30.7 \%)$ & $140(69.3 \%)$ & \\
\hline Present & $72(38.1 \%)$ & $117(61.9 \%)$ & \\
\hline Tumor budding & & & 0.795 \\
\hline Absent/Low/intermediate-grade (0 9 buds/×200) & $79(33.3 \%)$ & $155(66.2 \%)$ & \\
\hline High-grade $(\geq 10$ buds/×200) & $55(35.0 \%)$ & $102(65.0 \%)$ & \\
\hline T category & & & 0.045 \\
\hline pT1 and pT2 & $18(24.3 \%)$ & $56(75.7 \%)$ & \\
\hline pT3 and pT4 & $116(36.6 \%)$ & $201(63.4 \%)$ & \\
\hline Nodal status & & & 0.119 \\
\hline Negative & $51(30.0 \%)$ & $119(70.0 \%)$ & \\
\hline Positive & $83(37.6 \%)$ & $138(62.4 \%)$ & \\
\hline Stage * & & & 0.119 \\
\hline $\mathrm{I}$ & $13(22.8 \%)$ & $44(77.2 \%)$ & \\
\hline II & $37(33.3 \%)$ & $74(66.7 \%)$ & \\
\hline III & $72(36.4 \%)$ & $126(63.6 \%)$ & \\
\hline IV & $12(48.0 \%)$ & $13(52.0 \%)$ & \\
\hline
\end{tabular}

${ }^{*}$ AJCC 8 th edition.

\subsection{Prognostic Significance of SSBP2 Expression}

The OS of CRC patients with a loss of SSBP2 expression was significantly shorter $(p=0.038$, Figure 3A). However, SSBP2 expression did not affect the RFS ( $p=0.368$, Figure 3B). The univariate survival analysis for OS showed that SSBP2 expression, age, sex, pT category, nodal status, stage, histologic grade, lymphatic invasion, vascular invasion, perineural invasion, and tumor budding were significantly associated with OS ( $p<0.05$ for all cases) (Table 3). Multivariate Cox regression analysis, including SSBP2 expression, age, sex, pT category, nodal status, histologic grade, lymphatic invasion, vascular invasion, perineural invasion, and tumor budding, revealed that age $(p<0.001)$, sex $(p=0.004)$, and vascular invasion $(p<0.001)$ were independent prognostic factors for a poor OS, while SSBP2 expression was not statistically significant (Table 3). 

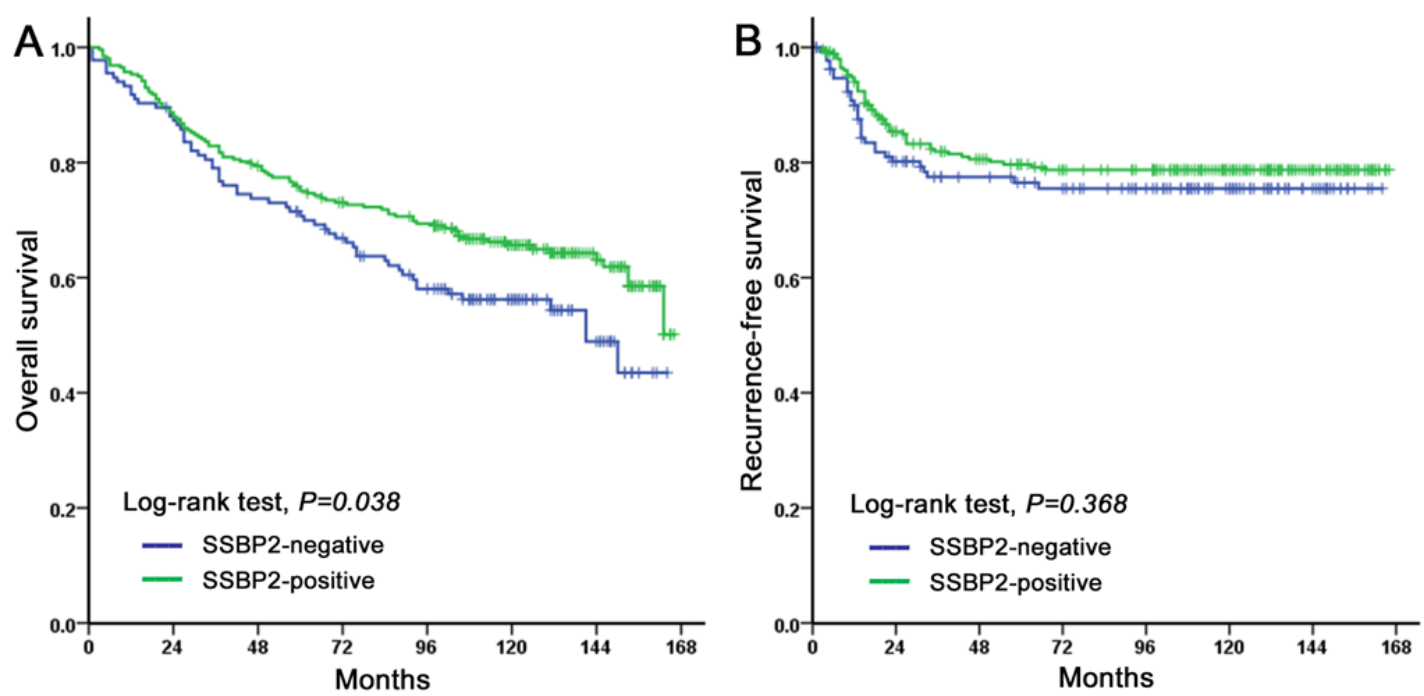

Figure 3. Kaplan-Meier analysis of SSBP2 expression in CRC patients. Overall survival (A) was shorter in patients showing a loss of SSBP2 expression compared to those showing a positive SSBP2 expression. Recurrence-free survival (B) was not associated with SSBP2 expression.

Table 3. Univariate and multivariate Cox regression analysis for overall survival in colorectal adenocarcinoma patients $(n=391)$.

\begin{tabular}{ccccccc}
\hline & \multicolumn{3}{c}{ Univariate Analysis } & \multicolumn{3}{c}{ Multivariate Analysis } \\
\hline Variables & HR & $\mathbf{9 5 \% ~ C I ~}$ & $\boldsymbol{p}$-Value & HR & $\mathbf{9 5 \% ~ C I ~}$ & $p$-Value \\
\hline SSBP2 (positive vs. negative) & 1.406 & $1.017-1.944$ & 0.038 & 1.190 & $0.850-1.666$ & 0.311 \\
Age (<65 vs. $\geq 65)$ & 2.810 & $1.996-3.956$ & $<0.001$ & 3.196 & $2.261-4.518$ & $<0.001$ \\
Sex (Female vs. Male) & 1.508 & $1.076-2.114$ & 0.017 & 1.643 & $1.167-2.312$ & 0.004 \\
pT category (1,2 vs. 3,4) & 1.036 & $1.013-1.060$ & 0.002 & 1.015 & $0.991-1.041$ & 0.225 \\
Nodal status (negative vs. positive) & 1.046 & $1.017-1.075$ & 0.002 & 0.975 & $0.889-1.070$ & 0.597 \\
Stage * (I, II vs. III, IV) & 1.025 & $1.010-1.041$ & 0.001 & & & \\
Histological grade (1,2 vs. 3) & 1.664 & $1.210-2.289$ & 0.002 & 1.384 & $0.975-1.964$ & 0.069 \\
Lymphatic invasion (absent vs. present) & 1.769 & $1.273-2.456$ & 0.001 & 1.571 & $0.520-4.749$ & 0.424 \\
Vascular invasion (absent vs. present) & 2.768 & $1.964-3.901$ & $<0.001$ & 2.220 & $1.520-3.244$ & $<0.001$ \\
Perineural invasion (absent vs. present) & 1.805 & $1.308-2.491$ & $<0.001$ & 1.244 & $0.845-1.831$ & 0.268 \\
Tumor budding (Absent/Low/intermediate vs. High) & 1.452 & $1.058-1.993$ & 0.021 & 1.102 & $0.777-1.562$ & 0.586 \\
\hline
\end{tabular}

* AJCC 8th edition. Abbreviation: HR, hazard ratio; 95\% CI, 95\% confidence interval.

\section{Discussion}

In this study, we showed that SSBP2 expression is significantly associated with OS and poor prognostic factors, such as vascular invasion and a high $\mathrm{pT}$ category.

SSBP2 is downregulated in several malignancies, such as esophageal squamous cell carcinoma, prostate cancer, and acute myeloid leukemia, and in previous studies, it has been speculated that promoter methylation may be the main mechanism of loss of SSBP2 expression. Recent studies have revealed that SSBP2 is one of the genes that are downregulated by the methylation pathway $[18,20,21,24,36]$. In 2011, Huang et al. compared SSBP2 methylation in normal and tumor tissues in 20 pairs of esophageal squamous cell carcinoma and matched normal esophageal tissues using TaqMan-MSP analysis, and a higher degree of SSBP2 methylation in paired tumors than in paired normal tissues was observed in 15 of 20 esophageal squamous cell carcinoma patients [18]. Jun-Wei et al. reported that the SSBP2 promoter region was hypermethylated in $61.4 \%$ (54 of 88 ) of prostate cancer cases, whereas none of the 23 benign prostatic hyperplasia cases showed hypermethylation [21]. They further examined the SSBP2 expression pattern using immunohistochemistry and showed that SSBP2 was significantly downregulated in most of the primary prostate cancer tissues, compared with normal prostate tissues. In addition, another study was conducted to identify a panel of epigenetic biomarkers that can distinguish cholecystitis from gallbladder cancer patients. This study revealed 
that promoter methylation statuses of SSBP2 $(p=0.01)$ were significantly different in patients with gallbladder cancer when compared to those of patients with cholecystitis [20]. Furthermore, in ovarian cancer, SSBP2 methylation was found in 9\% of tumor cases, whereas no cases showed methylation of the SSBP2 promoter in normal tissues [37].

The prognostic impact of SSBP2 expression in CRC has been mentioned in only a few studies. Shannon et al. reported that patients with a lower expression of SSBP2 were potentially correlated with a poorer OS and a shorter DFS, compared to those with a higher expression, using IHC. However, these results were not statistically significant. According to the article, the authors determined the staining results semi-quantitatively based on the staining intensity and percentage of stained tumor cells. Although patients with a lower expression of SSBP2 potentially have a poorer OS and DFS, they did not reach statistical significance (median OS, 29.8 months vs. 42.3 months for a low and high expression, respectively, HR 1.886, 95\% CI 0.812-4.378, $p=0.140$; median DFS, 14 months vs. 30 months for a low and high expression, respectively; HR 1.913; 95\% CI, 0.825-4.437; $p=0.131$ ) [27]. Perilli et al. studied the changes in expression of transcription factors, such as HIST1H2BH, NABP1 (also known as SSBP2), RND3, and TRIO genes after miR-182 silencing of oncogenic miR-182. As a result, all of them showed a significant upregulation, as confirmed using transcript-specific qRT-PCR assays. In particular, the SSBP2 gene showed a remarkably high expression in the anti-miR-182-treated tumorigenic cell line. Interestingly, they also reported that a significant decrease in the SSBP2 mRNA levels was identified in primary CRC samples compared to matched normal colon mucosa samples [28].

In this study, we found that the SSBP2 expression pattern is correlated with the OS and several poor clinicopathological factors of the patient. An SSBP2 expression loss was found in $34.3 \%$ of primary adenocarcinoma and $76.3 \%$ of metastatic adenocarcinoma tissues; however, no expression loss was found in matched normal colonic mucosa and adenoma cases. These results suggested that the loss of SSBP2 expression is possibly associated with aggressive clinical behavior of CRC.

In addition, it is meaningful to combine the results of the previous study [28]. Although Perilli et al. conducted a study with many other transcription factors besides SSBP2, only in the case of SSBP2 it was reported that the mRNA level was markedly reduced in colorectal cancer compared to normal tissues. This result is consistent with the present study, which performed immunohistochemical staining using SSBP2 antibody. This can be positively evaluated in that it suggests the possibility of performing a prognosis-related test for colorectal cancer by a simple method such as immunohistochemistry.

Further studies on SSBP2 promoter methylation and its association with SSBP2 expression in a large cohort of CRC patients using fresh tissues are necessary to understand the mechanism underlying SSBP2-related carcinogenesis. The findings of our study lay the foundation for designing future studies. If the same results are gathered in more groups in the future and target therapy studies for SSBP2 are progressed, it will be a cornerstone for the opening of a new treatment for colorectal cancer, which remains a challenge.

\section{Conclusions}

In conclusion, we showed that SSBP2 expression was significantly decreased in colorectal adenocarcinoma and metastatic carcinoma tissues and was associated with poor prognostic factors. SSBP2 acts as a tumor suppressor and may be used as a prognostic biomarker in colorectal cancer.

Author Contributions: Y.C. performed all experiments, analyzed and interpreted results, and wrote the paper. Y.C. and H.K. acquired pathological data. H.K., S.B., K.J., S.S.P., and S.-J.S. acquired clinical data and revised the paper critically for important intellectual content. S.S.P. and S.-J.S. designed the project, supervised research, edited and approved the final version of the paper. All authors read and approved the final version of the manuscript.

Funding: This work was supported by the National Research Foundation of Korea (NRF) grant funded by the Korea government (MSIT) (2017R1C1B5017930).

Conflicts of Interest: The authors declare that they have no competing interests.

Availability of Data and Materials: All data generated or analyzed during this study are included in this published article.: 


\section{References}

1. Ferlay, J.; Soerjomataram, I.; Dikshit, R.; Eser, S.; Mathers, C.; Rebelo, M.; Parkin, D.M.; Forman, D.; Bray, F. Cancer incidence and mortality worldwide: Sources, methods and major patterns in GLOBOCAN 2012. Int. J. Cancer 2015, 136, E359-E386. [CrossRef] [PubMed]

2. Muller, M.F.; Ibrahim, A.E.; Arends, M.J. Molecular pathological classification of colorectal cancer. Virchows Arch. Int. J. Pathol. 2016, 469, 125-134. [CrossRef] [PubMed]

3. Poulogiannis, G.; Ichimura, K.; Hamoudi, R.A.; Luo, F.; Leung, S.Y.; Yuen, S.T.; Harrison, D.J.; Wyllie, A.H.; Arends, M.J. Prognostic relevance of DNA copy number changes in colorectal cancer. J. Pathol. 2010, 220, 338-347. [CrossRef] [PubMed]

4. Arends, M.J. Pathways of colorectal carcinogenesis. Appl. Immunohistochem Mol. Morphol. 2013, 21, 97-102.

5. Markowitz, S.D.; Bertagnolli, M.M. Molecular origins of cancer: Molecular basis of colorectal cancer. N. Engl. J. Med. 2009, 361, 2449-2460. [CrossRef]

6. Jones, P.A.; Baylin, S.B. The fundamental role of epigenetic events in cancer. Nat. Rev. Genet. 2002, 3, 415-428. [CrossRef]

7. Hoque, M.O.; Kim, M.S.; Ostrow, K.L.; Liu, J.; Wisman, G.B.; Park, H.L.; Poeta, M.L.; Jeronimo, C.; Henrique, R.; Lendvai, A.; et al. Genome-wide promoter analysis uncovers portions of the cancer methylome. Cancer Res. 2008, 68, 2661-2670. [CrossRef]

8. Powell, S.M.; Zilz, N.; Beazer-Barclay, Y.; Bryan, T.M.; Hamilton, S.R.; Thibodeau, S.N.; Vogelstein, B.; Kinzler, K.W. APC mutations occur early during colorectal tumorigenesis. Nature 1992, 359, $235-237$. [CrossRef]

9. $\quad$ Esteller, M.; Sparks, A.; Toyota, M.; Sanchez-Cespedes, M.; Capella, G.; Peinado, M.A.; Gonzalez, S.; Tarafa, G.; Sidransky, D.; Meltzer, S.J.; et al. Analysis of adenomatous polyposis coli promoter hypermethylation in human cancer. Cancer Res. 2000, 60, 4366-4371.

10. Evrard, C.; Tachon, G.; Randrian, V.; Karayan-Tapon, L.; Tougeron, D. Microsatellite Instability: Diagnosis, Heterogeneity, Discordance, and Clinical Impact in Colorectal Cancer. Cancers (Basel) 2019, 11, 1567. [CrossRef]

11. Sinicrope, F.A.; Sargent, D.J. Molecular pathways: Microsatellite instability in colorectal cancer: Prognostic, predictive, and therapeutic implications. Clin. Cancer Res. 2012, 18, 1506-1512. [CrossRef] [PubMed]

12. Tougeron, D.; Mouillet, G.; Trouilloud, I.; Lecomte, T.; Coriat, R.; Aparicio, T.; Des Guetz, G.; Lecaille, C.; Artru, P.; Sickersen, G.; et al. Efficacy of Adjuvant Chemotherapy in Colon Cancer With Microsatellite Instability: A Large Multicenter AGEO Study. J. Natl. Cancer Inst. 2016, 108. [CrossRef] [PubMed]

13. Sargent, D.J.; Marsoni, S.; Monges, G.; Thibodeau, S.N.; Labianca, R.; Hamilton, S.R.; French, A.J.; Kabat, B.; Foster, N.R.; Torri, V.; et al. Defective mismatch repair as a predictive marker for lack of efficacy of fluorouracil-based adjuvant therapy in colon cancer. J. Clin. Oncol. 2010, 28, 3219-3226. [CrossRef] [PubMed]

14. Jover, R.; Zapater, P.; Castells, A.; Llor, X.; Andreu, M.; Cubiella, J.; Pinol, V.; Xicola, R.M.; Bujanda, L.; Rene, J.M.; et al. Mismatch repair status in the prediction of benefit from adjuvant fluorouracil chemotherapy in colorectal cancer. Gut 2006, 55, 848-855. [CrossRef]

15. Barbalan, A.; Nicolaescu, A.C.; Magaran, A.V.; Mercut, R.; Balasoiu, M.; Bancescu, G.; Serbanescu, M.S.; Lazar, O.F.; Saftoiu, A. Immunohistochemistry predictive markers for primary colorectal cancer tumors: Where are we and where are we going? Rom. J. Morphol. Embryol. 2018, 59, 29-42.

16. Castro, P.; Liang, H.; Liang, J.C.; Nagarajan, L. A novel, evolutionarily conserved gene family with putative sequence-specific single-stranded DNA-binding activity. Genomics 2002, 80, 78-85. [CrossRef]

17. Fairman, J.; Wang, R.Y.; Liang, H.; Zhao, L.; Saltman, D.; Liang, J.C.; Nagarajan, L. Translocations and deletions of 5q13.1 in myelodysplasia and acute myelogenous leukemia: Evidence for a novel critical locus. Blood 1996, 88, 2259-2266. [CrossRef]

18. Huang, Y.; Chang, X.; Lee, J.; Cho, Y.G.; Zhong, X.; Park, I.S.; Liu, J.W.; Califano, J.A.; Ratovitski, E.A.; Sidransky, D.; et al. Cigarette smoke induces promoter methylation of single-stranded DNA-binding protein 2 in human esophageal squamous cell carcinoma. Int. J. Cancer 2011, 128, 2261-2273. [CrossRef]

19. Liang, H.; Samanta, S.; Nagarajan, L. SSBP2, a candidate tumor suppressor gene, induces growth arrest and differentiation of myeloid leukemia cells. Oncogene 2005, 24, 2625-2634. [CrossRef] 
20. Kagohara, L.T.; Schussel, J.L.; Subbannayya, T.; Sahasrabuddhe, N.; Lebron, C.; Brait, M.; Maldonado, L.; Valle, B.L.; Pirini, F.; Jahuira, M.; et al. Global and gene-specific DNA methylation pattern discriminates cholecystitis from gallbladder cancer patients in Chile. Future Oncol. 2015, 11, 233-249. [CrossRef]

21. Liu, J.W.; Nagpal, J.K.; Sun, W.; Lee, J.; Kim, M.S.; Ostrow, K.L.; Zhou, S.; Jeronimo, C.; Henrique, R.; Van Criekinge, W.; et al. ssDNA-binding protein 2 is frequently hypermethylated and suppresses cell growth in human prostate cancer. Clin. Cancer Res. 2008, 14, 3754-3760. [CrossRef] [PubMed]

22. Maldonado, L.; Brait, M.; Loyo, M.; Sullenberger, L.; Wang, K.; Peskoe, S.B.; Rosenbaum, E.; Howard, R.; Toubaji, A.; Albadine, R.; et al. GSTP1 promoter methylation is associated with recurrence in early stage prostate cancer. J. Urol. 2014, 192, 1542-1548. [CrossRef] [PubMed]

23. He, W.L.; Weng, X.T.; Wang, J.L.; Lin, Y.K.; Liu, T.W.; Zhou, Q.Y.; Hu, Y.; Pan, Y.; Chen, X.L. Association Between c-Myc and Colorectal Cancer Prognosis: A Meta-Analysis. Front. Physiol. 2018, 9, 1549. [CrossRef] [PubMed]

24. Michailidi, C.; Soudry, E.; Brait, M.; Maldonado, L.; Jaffe, A.; Ili-Gangas, C.; Brebi-Mieville, P.; Perez, J.; Kim, M.S.; Zhong, X.; et al. Genome-wide and gene-specific epigenomic platforms for hepatocellular carcinoma biomarker development trials. Gastroenterol. Res. Pr. 2014, 2014, 597164. [CrossRef]

25. Brait, M.; Banerjee, M.; Maldonado, L.; Ooki, A.; Loyo, M.; Guida, E.; Izumchenko, E.; Mangold, L.; Humphreys, E.; Rosenbaum, E.; et al. Promoter methylation of MCAM, ERalpha and ERbeta in serum of early stage prostate cancer patients. Oncotarget 2017, 8, 15431-15440. [CrossRef]

26. Andersen, C.L.; Christensen, L.L.; Thorsen, K.; Schepeler, T.; Sorensen, F.B.; Verspaget, H.W.; Simon, R.; Kruhoffer, M.; Aaltonen, L.A.; Laurberg, S.; et al. Dysregulation of the transcription factors SOX4, CBFB and SMARCC1 correlates with outcome of colorectal cancer. Br. J. Cancer 2009, 100, 511-523. [CrossRef]

27. Shannon, N.B.; Tan, J.W.; Tan, H.L.; Wang, W.; Chen, Y.; Lim, H.J.; Tan, Q.X.; Hendrikson, J.; Ng, W.H.; Loo, L.Y.; et al. A set of molecular markers predicts chemosensitivity to Mitomycin-C following cytoreductive surgery and hyperthermic intraperitoneal chemotherapy for colorectal peritoneal metastasis. Sci. Rep. 2019, 9, 10572. [CrossRef]

28. Perilli, L.; Tessarollo, S.; Albertoni, L.; Curtarello, M.; Pasto, A.; Brunetti, E.; Fassan, M.; Rugge, M.; Indraccolo, S.; Amadori, A.; et al. Silencing of miR-182 is associated with modulation of tumorigenesis through apoptosis induction in an experimental model of colorectal cancer. BMC Cancer 2019, $19,821$. [CrossRef]

29. Amin, M.B.; Edge, S.; Greene, F.; Byrd, D.R.; Brookland, R.K.; Washington, M.K.; Gershenwald, J.E.; Compton, C.C.; Hess, K.R.; Sullivan, D.C.; et al. AJCC Cancer Staging Manual, 8th ed.; Springer: New York, NY, USA, 2017.

30. Zlobec, I.; Steele, R.; Michel, R.P.; Compton, C.C.; Lugli, A.; Jass, J.R. Scoring of p53, VEGF, Bcl-2 and APAF-1 immunohistochemistry and interobserver reliability in colorectal cancer. Mod. Pathol. 2006, 19, 1236-1242. [CrossRef]

31. Zlobec, I.; Vuong, T.; Compton, C.C. The predictive value of apoptosis protease-activating factor 1 in rectal tumors treated with preoperative, high-dose-rate brachytherapy. Cancer 2006, 106, 284-286. [CrossRef]

32. Rosati, G.; Chiacchio, R.; Reggiardo, G.; De Sanctis, D.; Manzione, L. Thymidylate synthase expression, p53, bcl-2, Ki-67 and p27 in colorectal cancer: Relationships with tumor recurrence and survival. Tumour Biol. J. Int. Soc. Oncodevelopmental Biol. Med. 2004, 25, 258-263. [CrossRef] [PubMed]

33. Galizia, G.; Lieto, E.; Ferraraccio, F.; Orditura, M.; De Vita, F.; Castellano, P.; Imperatore, V.; Romano, C.; Ciardiello, F.; Agostini, B.; et al. Determination of molecular marker expression can predict clinical outcome in colon carcinomas. Clin. Cancer Res. 2004, 10, 3490-3499. [CrossRef] [PubMed]

34. Okonkwo, A.; Musunuri, S.; Talamonti, M.; Benson, A., 3rd; Small, W., Jr.; Stryker, S.J.; Rao, M.S. Molecular markers and prediction of response to chemoradiation in rectal cancer. Oncol. Rep. 2001, 8, 497-500. [CrossRef]

35. Giatromanolaki, A.; Stathopoulos, G.P.; Tsiompanou, E.; Papadimitriou, C.; Georgoulias, V.; Gatter, K.C.; Harris, A.L.; Koukourakis, M.I. Combined role of tumor angiogenesis, bcl-2, and p53 expression in the prognosis of patients with colorectal carcinoma. Cancer 1999, 86, 1421-1430. [CrossRef] 
36. Ahmed, H. Promoter Methylation in Prostate Cancer and its Application for the Early Detection of Prostate Cancer Using Serum and Urine Samples. Biomark Cancer 2010, 2010, 17-33. [CrossRef] [PubMed]

37. Brait, M.; Maldonado, L.; Noordhuis, M.G.; Begum, S.; Loyo, M.; Poeta, M.L.; Barbosa, A.; Fazio, V.M.; Angioli, R.; Rabitti, C.; et al. Association of promoter methylation of VGF and PGP9.5 with ovarian cancer progression. PLoS ONE 2013, 8, e70878. [CrossRef]

Publisher's Note: MDPI stays neutral with regard to jurisdictional claims in published maps and institutional affiliations.

(C) 2020 by the authors. Licensee MDPI, Basel, Switzerland. This article is an open access article distributed under the terms and conditions of the Creative Commons Attribution (CC BY) license (http://creativecommons.org/licenses/by/4.0/). 